\title{
Effects of Plastic Stress on Transformation Plasticity and Microstructure of a Carbide-Free Bainite Steel
}

\author{
Mengen Liu ${ }^{1} \cdot$ Ying $\mathrm{Ma}^{3} \cdot$ Guang Xu${ }^{2} \cdot$ Guangyu Cai ${ }^{1} \cdot$ Mingxing Zhou ${ }^{1} \cdot \mathrm{Xi}_{\text {Zhang }}{ }^{1}$
}

Received: 23 July 2018 / Revised: 3 January 2019 / Accepted: 6 February 2019 / Published online: 14 February 2019

(c) ASM International 2019

\begin{abstract}
Thermal simulation experiments were conducted, the microstructures were observed by scanning electron microscope (SEM) and transmission electron microscopy (TEM), and the bainite orientation was examined by electron backscattering diffraction (EBSD). The effects of plastic stress on transformation plasticity (TP) strain were investigated. The results show that the TP strain increases nonlinearly with the applied stress. It increases slowly versus the stress in the elastic region, and there is a sharp increase in TP strain if the stress exceeds the parent austenite yield strength because of the combined effect of prior deformation and stress. As the stress continues to increase, the bainite transformation amount decreases, leading to a slower increasing rate of TP strain. In addition, it is confirmed by EBSD that the TP strain is accompanied by the variant selection in microstructures, so that the occurrence of TP is consistent with the Magee mechanism. Moreover, the TP strain is more obvious at lower transformation temperatures due to the increased bainite transformation amount and more organized bainite structure.
\end{abstract}

Keywords Transformation plasticity $\cdot$ Bainite transformation $\cdot$ Variant selection $\cdot$ Stress $\cdot$ Prior deformation

Mingxing Zhou

kdmingxing@163.com

Mengen Liu

cqhnjs@163.com

Ying Ma

mynylg@163.com

Guang Xu

xuguang@wust.edu.cn

Guangyu Cai

caiguangyu71@163.com

Xi Zhang

zhangxi_nist@163.com

1 School of Mechanical and Automotive Engineering, Nanyang Institute of Technology, 80 Changjiang Road, Wancheng District, Nanyang 473004, China

2 The State Key Laboratory of Refractories and Metallurgy, Hubei Collaborative Innovation Center for Advanced Steels, Wuhan University of Science and Technology, Wuhan 430081, China

3 School of Civil Engineering, Nanyang Institute of Technology, Nanyang 473004, China

\section{Introduction}

Internal stresses are always generated in steels during the quenching process, so the phase transformations, such as bainite and martensite transformations, during quenching and austempering are under the effect of stress. Bainite, which has a combination of high strength and good toughness, is an important constituent in advanced high strength steels. Therefore, the effect of stress on bainite transformation has attracted much attention in recent years.

It was claimed that axial stress increases bainite transformation amount and accelerates bainite transformation kinetics [1-6]. Carbide-free bainite steel, which has excellent strength and toughness combination, is a new generation of advanced high strength steels [6-11]. Authors' previous studies confirmed the acceleration of stress on bainite transformation in a carbide-free bainite steel and found that the acceleration of stress on bainite transformation varies nonlinearly with the stress [12-15]. Also, a model was established to describe the bainite transformation kinetics under the effect of stress [16]. In addition, another interesting phenomenon was found, i.e., the samples were plastically deformed during bainite transformation with stress even it is smaller than the yield strength of parent austenite. The 
plastic deformation formed during transformation is termed as transformation plasticity (TP) strain.

The effect of stress on TP strain has been investigated in some researches. Shipway and his co-workers found that the TP strain increases with the elastic stress (i.e., below the yield strength of parent austenite) [2, 17]. In addition, TP strain is larger when the bainite transformation proceeds in larger parent austenite grains [15]. Recently, in situ characterization of TP strain was conducted by digital image correlation (DIC) $[18,19]$. However, above studies only investigated the elastic stresses, whereas the effects of plastic stresses, which are higher than the yield strength of parent austenite, on TP strain were not clarified. For the latter case, plastic deformation occurs before bainite transformation and the subsequent bainite transformation is influenced by two factors, i.e., the applied stress and the prior deformation (noted that this is not TP strain). Therefore, one purpose of this work is to clarify the effects of plastic stress on TP strain in the bainite steel.

In addition, there are mainly two mechanisms to explain the occurrence of TP strain, i.e., Magee mechanism [20] and Greenwood-Johnson mechanism [21]. The Magee mechanism is related to the formation of selected bainite or martensite variants resulting from the applied stress $[4,17$, 20]. In addition, for Greenwood-Johnson mechanism, the TP strain is associated with the micro-deformation of the weaker phase because the volume between the parent and the product phases is different [21, 22]. Rees et al. and Uslu et al. [17, 23] believed that Magee mechanism is suitable to explain the occurrence of TP strain in bainite steels, whereas Han et al. and Liu et al. [24, 25] proposed TP strain models based on Greenwood-Johnson mechanism. It is meaningful to investigate the mechanisms for the occurrence of TP strain in the bainite steel.

Different stress levels and transformation temperatures were set in the present work. The effects of plastic stress on the TP strain and microstructure of a carbide-free bainite steel were studied, and the mechanisms for the occurrence of TP strain in the bainite steel were analyzed.

\section{Materials and Methods}

\section{Materials}

The composition of the tested steel is Fe-0.45C-2.0Si-2.8Mn $\mathrm{wt} \%$. The continuous cooling transformation (CCT) curve, the bainite starting (Bs) temperature, and the martensite starting (Ms) temperature of the tested steel are determined by JMatPro software, as is shown in Fig. 1. It indicates that ferrite and pearlite transformations are absent at the cooling rate larger than $10^{\circ} \mathrm{C} / \mathrm{s}$. In addition, the Bs and Ms temperatures of the tested steel are 450 and $225^{\circ} \mathrm{C}$, respectively.

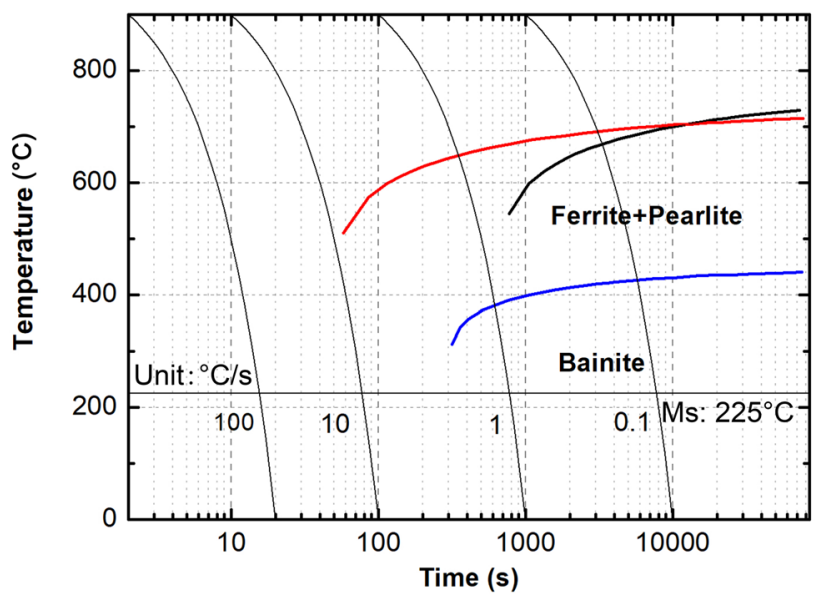

Fig. 1 CCT curve of the tested steel

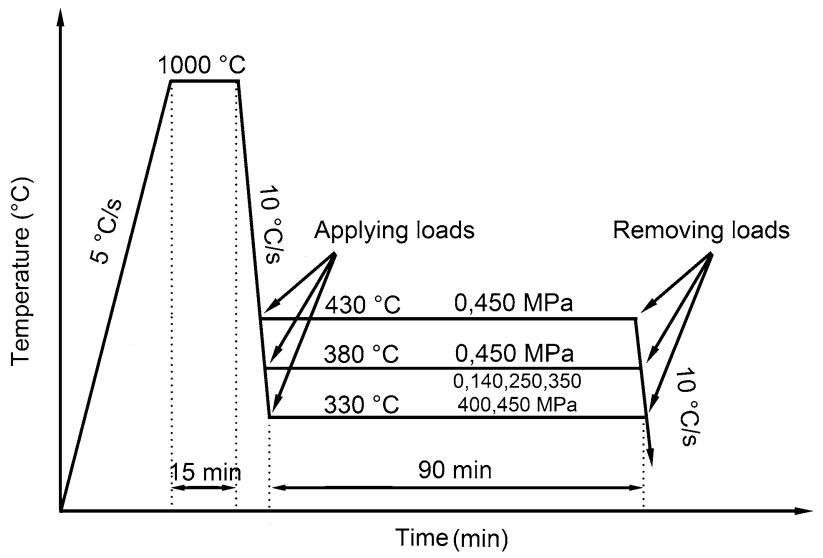

Fig. 2 Experimental procedures

\section{Thermal Simulations}

A Gleeble 3800 simulator was used for isothermal bainite transformation experiments. The specimens were cylinders with $15 \mathrm{~mm}$ in length and $10 \mathrm{~mm}$ in diameter. As shown in Fig. 2, the samples were austenized at $1000{ }^{\circ} \mathrm{C}$, followed by isothermal bainite transformation at 330,380 , and $430{ }^{\circ} \mathrm{C}$. Different stresses (0-450 MPa) were applied to the specimens during bainite transformation in order to clarify the effects of stress on TP strain at different transformation temperatures. The stresses were quickly applied to the target value within $3 \mathrm{~s}$. Previous studies showed that the austenite yield strength of the experimental steel is between 155 and $175 \mathrm{MPa}$ at $430-330{ }^{\circ} \mathrm{C}$ [16], so that the applied stresses of 250-450 MPa cause plastic deformation before bainite transformation. Radial and axial dilatations of the samples were measured at the same time during the thermal simulations. 


\section{Microstructural Examination}

A field emission scanning electron microscopy (FESEM) was used to observe the microstructures of the samples after thermal simulations. In addition, electron backscattering diffraction (EBSD) analysis was carried out on the samples with different stress states to characterize the distribution of crystallographic orientations. Samples for EBSD examination was electropolished using an electrolyte consisted of $10 \mathrm{vol} \%$ perchloric acid and 90 vol\% glacial acetic acid. In addition, transmission electron microscopy (TEM) was used to observe bainite structure. Thin foils for TEM observation were mechanically ground to about $40 \mu \mathrm{m}$ thickness and then thinned using a twin jet electro-polisher.

\section{Results and Discussions}

\section{Microstructure}

The typical microstructures of the samples with and without stresses are shown in Fig. 3. The microstructure is consisted of bainite ferrite (BF), retained austenite (RA), and martensite (M). TEM microstructure (Fig. 4) confirms the phase constituents. Authors' previous study [26] and other similar microstructure $[3,9]$ also showed that the microstructure of the studied steel consists of BF, M, and RA. BF is separated by RA, as is shown in Fig. 4c. There is no carbide observed due to the large amount of silicon added in the tested steel

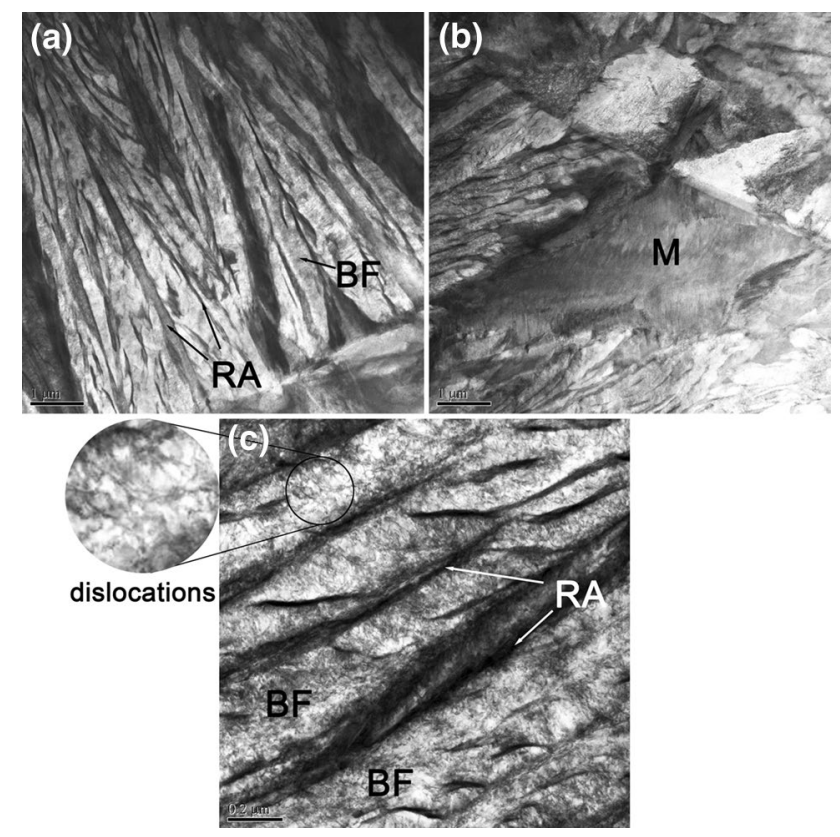

Fig. 4 TEM morphologies of the sample without stress
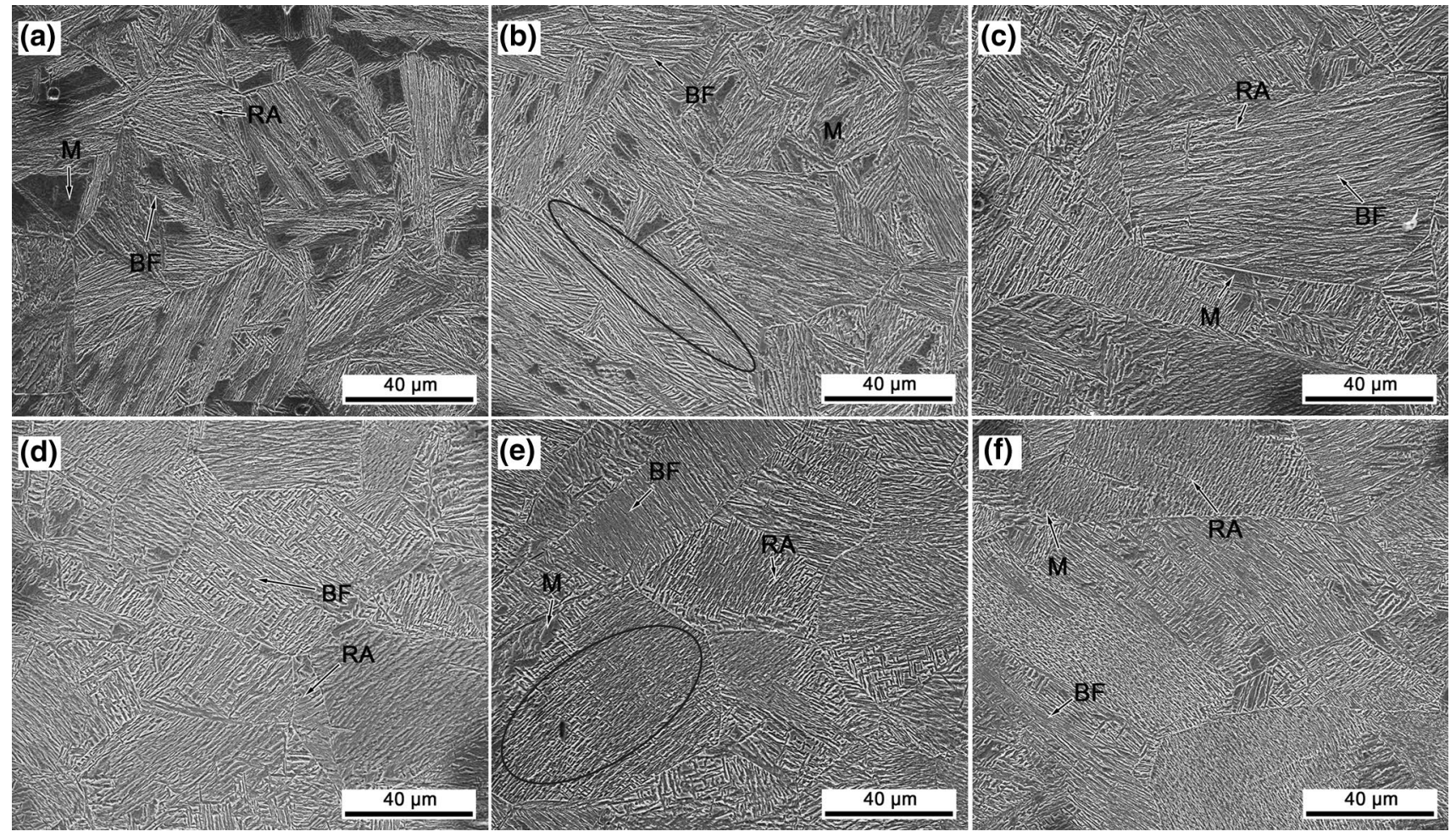

Fig. 3 Typical microstructures of the samples with different stresses: (a) without stress; (b) $140 \mathrm{MPa}$; (c) $250 \mathrm{MPa}$; (d) $350 \mathrm{MPa}$; (e) $400 \mathrm{MPa}$; (f) $450 \mathrm{MPa}$ 
$[2,26]$. There are many dislocations within the BF which provide high strength for bainite structure [27]. In addition, bainite sheaves distribute at random in the sample without stress (Fig. 3a). By contrast, alignments of bainite sheaves are observed in the samples with stresses (for example, marked areas in Fig. 3). The distribution of bainite sheaves becomes more anisotropic as the stress increases.

The orientation of bainite is further studied by EBSD technique. The orientation imaging maps of different samples are shown in Fig. 5. The colors represent different crystallographic orientations. The orientation imaging map of the sample without stress is colorful (Fig. 5a), indicating that there are many kinds of bainite variants. When an elastic stress is applied (Fig. 5b), the color category decreases, meaning that bainite transformation under elastic stress leads to a nonrandom distribution of bainite variants. When a plastic stress is applied (Fig. 5c), the bainite sheaves distribute obviously along similar direction and the bainite orientation is much more anisotropic. The inverse pole figures (Fig. 6) clearly show that transformation texture with strong peaks develops in the samples with stresses and the maximum intensity increases with the stress. The amount of bainite variants decreases in the sample with elastic and plastic stresses, indicating the occurrence of variant selection.

The applied stress provides additional mechanical driving force for the bainite transformation and thus accelerates the transformation [2, 3]. However, the mechanical driving force distributed on each bainite variant is different. The variants that comply with the stress obtain larger driving force and their growth is favored, whereas others are hindered, so that variant selection develops in the samples with stress. In addition, when a plastic stress is applied, the austenite is plastically deformed before bainite transformation, so that the subsequent transformation is affected by both stress and deformation. It was reported that prior deformation also decreases the number of bainite variants and leads to variant selection [28]. Therefore, under the combined effects of stress and deformation, obvious variant selection develops when a plastic stress is applied, as is shown in Figs. 5 and 6.

\section{TP Strain}

The radial strains and axial strains of the samples are shown in Fig. 7a. The radial strain almost coincides with
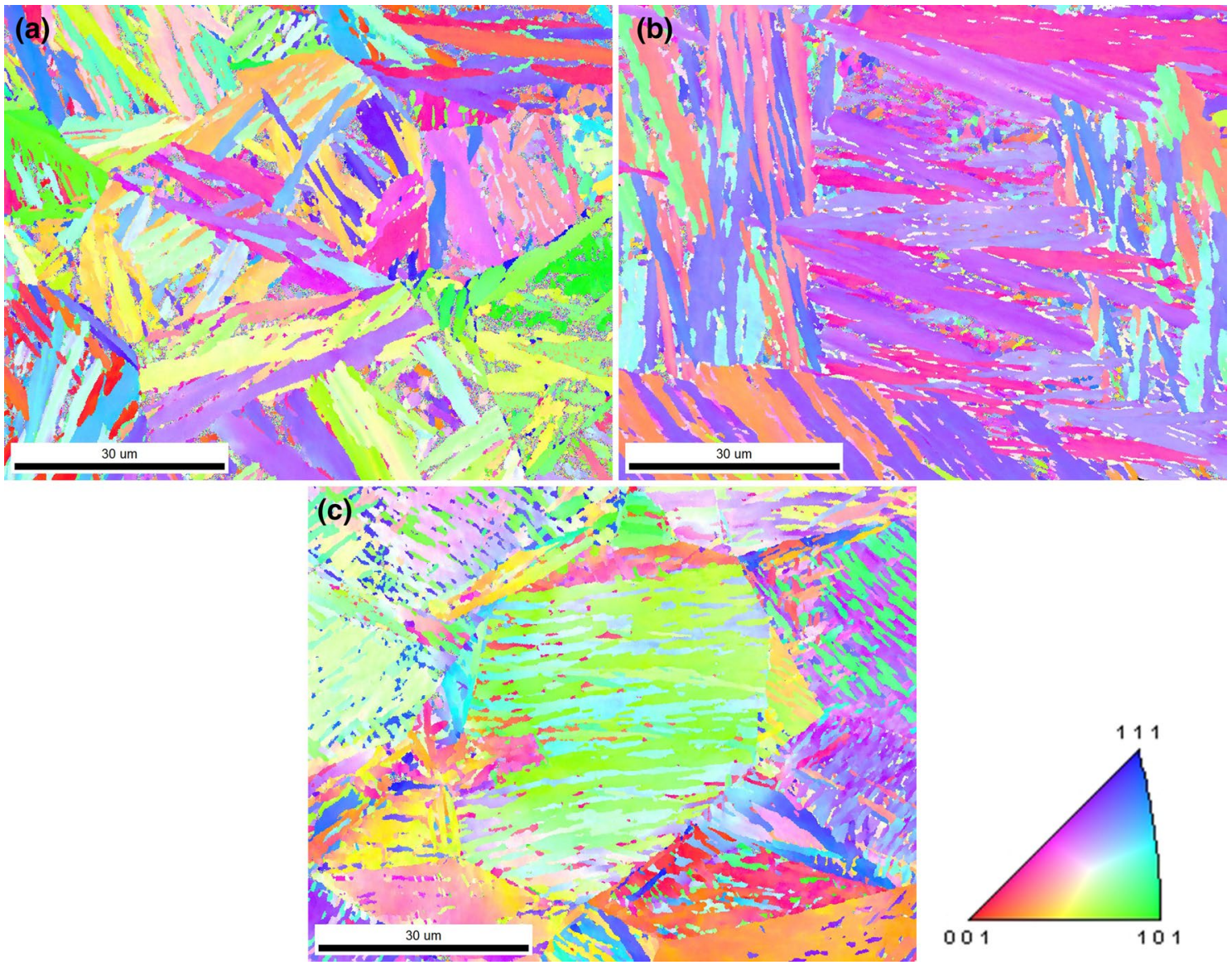

Fig. 5 Orientation imaging maps of bainite in the samples with different stresses: (a) without stress; (b) $140 \mathrm{MPa}$; (c) $450 \mathrm{MPa}$ 
Fig. 6 Inverse pole figures for the samples with different stresses: (a) without stress; (b) $140 \mathrm{MPa}$; (c) $450 \mathrm{MPa}$
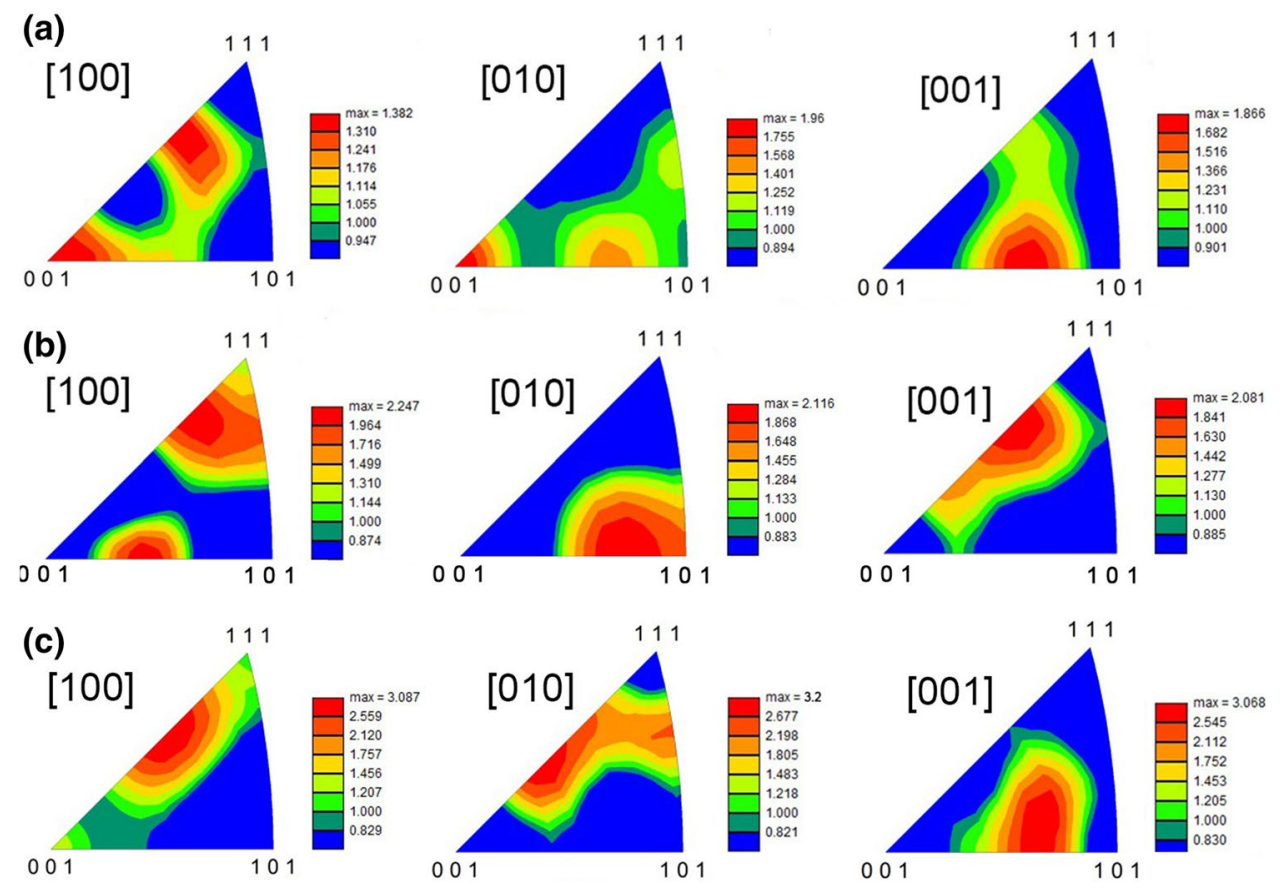
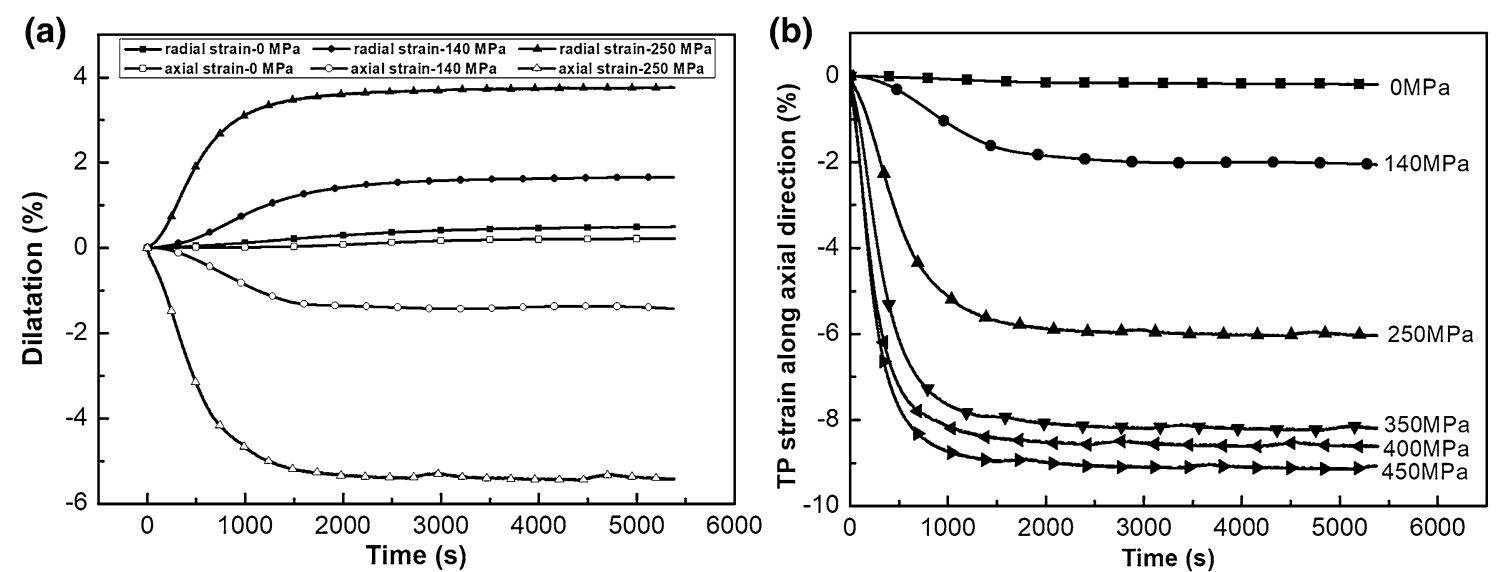

Fig. 7 (a) The radial and axial strains of different samples; (b) TP strain along axial direction in different samples

the axial strain in the sample without stress, indicating that the shape change of the sample during bainite transformation is isotropic. However, when the bainite transformation is affected by elastic or plastic stresses, the radial strain becomes separated from the axial strain, demonstrating that plastic deformation, i.e., TP strain, develops during bainite transformation. The samples used in thermal simulation experiments have radial symmetry, so that it may be assumed that the strains in all radial directions are identical and the volume strain $(\Delta V / V)$ can be calculated by Eq (1) [2]. The axial strain of the sample includes TP strain in the axial direction and the volume strain in the axial direction. The volume strain is caused by the change of lattice type from $\gamma$ phase to $\alpha$ phase. Assuming that the volume change is isotropic, the TP strain in the axial direction can be given by Eq (2) [2]:

$\Delta V / V=\left(1+\varepsilon_{L}\right)\left(1+\varepsilon_{R}\right)^{2}-1$

$\varepsilon_{p}=\varepsilon_{L}-\frac{1}{3} \times(\Delta V / V)$

where $\varepsilon_{\mathrm{P}}$ is the TP strain, $\varepsilon_{\mathrm{L}}$ is the axial strain, and $\varepsilon_{\mathrm{R}}$ is the radial strain of the specimen. $\Delta V$ is the volume change, $V$ is the original volume, and $\Delta V / V$ is the volume strain of the specimen. The results in Fig. 7b show that in the samples without stress, the TP strain is almost zero during the whole bainite transformation, whereas for the stress-affected 
samples, the TP strain increases along with the bainite transformation. Noted that the TP strain no longer increases when the bainite transformation ceases, so that the magnitude of TP strain is associated with the degree of bainite transformation.

It can be found in Figs. 5, 6, and 7 that where there is variant selection in the microstructure, there is TP strain in the sample, i.e., the TP strain is accompanied by the variant selection. Therefore, the occurrence of TP strain in carbidefree bainite steel can be well explained by the Magee mechanism $[4,17,20]$, in which the TP strain is related to the variant selection. Detailed discussions about Magee mechanism are given below. As shown in Fig. 8, invariant plane strain (IPS) is always used to describe the shape change in the transformed region caused by bainite growth. IPS is consisted of a large shear component $(\mathrm{s} \approx 0.26)$ and a small dilatational strain $(\delta \approx 0.03)$ directed normal to the habit plane [29]. According to the Magee mechanism, the shear strain can be canceled out when the variants orientation is random because for every shear there is somewhere an opposing shear of equal magnitude. In this case, the transformation strain is mainly caused by the dilatational component, which is usually addictive, so the radial strain should be similar to the axial strain, i.e., the dilatation of the sample during transformation is isotropic (Fig. 7). On the other hand, when the variant selection occurs, the shear component will accumulate and contribute to the transformation strain. Noted that the shear strain is as larger as 0.26 , so that the sample is plastically deformed during the transformation, i.e., TP strain forms (Fig. 7). In summary, the occurrence of TP strain in the carbide-free bainite steel is consistent with the Magee mechanism.

The final TP strains in different samples are given in Fig. 9 (the line with solid square). It shows that the TP strain increases nonlinear with the applied stress. The TP strain increases slowly with the applied stress in the elastic region (region A in Fig. 9) because the variant selection is not apparent. As the stress exceeds the austenite yield limit, obvious variant selection develops due to the combined effect of prior deformation and applied stress (Figs. 5

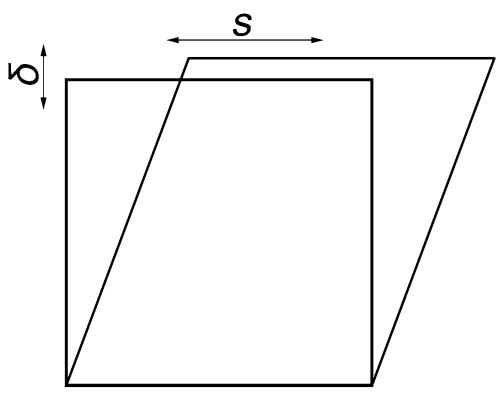

Fig. 8 Illustration of the invariant plane strain and 6), so there is a sharp increase in the TP strain (region B in Fig. 9). As the stress further increases, the increasing rate of TP strain slows down due to the decreased bainite transformation amount. The volume strains of different samples during bainite transformation (representing the bainite transformation amount) are also given in Fig. 9 (the line with open square). When the stress is above $350 \mathrm{MPa}$, the bainite transformation amount decreases with the increase in stress (detailed discussion about this is given in Ref. [12]), so the increasing rate of TP strain decreases. In addition, the TP strain as large as $9.1 \%$ is measured in the sample with $450 \mathrm{MPa}$ stress, meaning that the sample is obviously deformed due to the transformation.

Figure 10a shows the final TP strain of samples transformed at different temperatures. For the samples without stress, the TP strain is almost zero whatever the transformation temperature. When $400 \mathrm{MPa}$ plastic stress is applied,

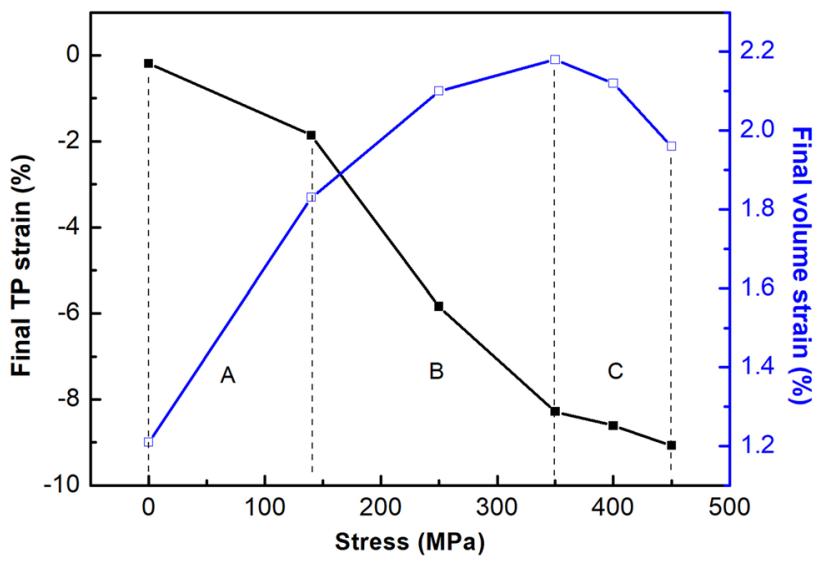

Fig. 9 The final TP strain and bainite transformation amount versus applied stress

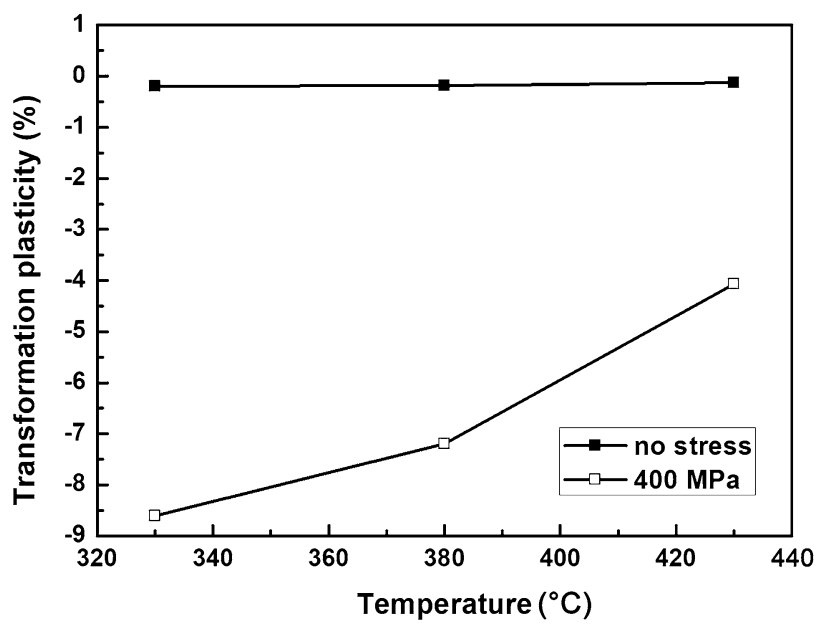

Fig. $10 \mathrm{TP}$ strain as a function of stress and transformation temperature 


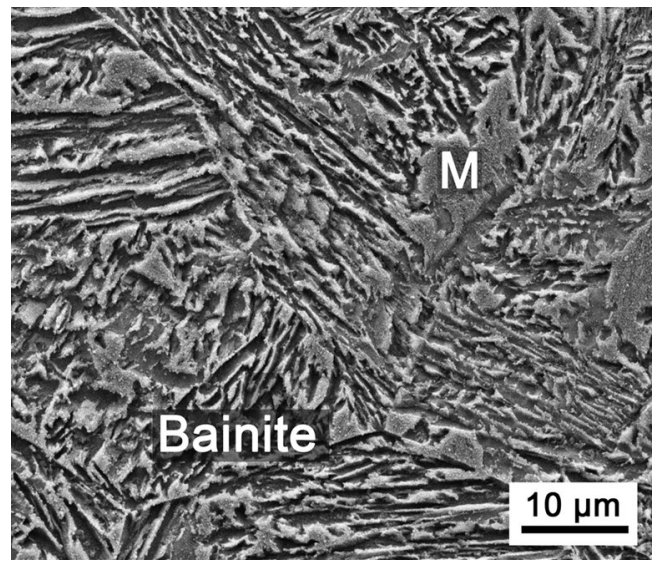

Fig. 11 Microstructure in the sample with $400 \mathrm{MPa}$ stress (transformation temperature: $430{ }^{\circ} \mathrm{C}$ )

the TP strain appears and it is larger at lower transformation temperatures. One reason is that the bainite transformation amount is larger at lower transformation temperatures. Also, when the transformation temperature is higher, the variant selection is not obvious even plastic stress is applied as is shown in Fig. 11. This may be because the parent austenite is plastically deformed by $400 \mathrm{MPa}$ stress, but recovery and recrystallization take place in the deformed austenite at higher transformation temperatures, so that the plastic stress has less effect on the variant selection and the TP strain is smaller.

Prior studies mainly focused on the effect of elastic stress on TP strain [4, 17, 24, 25]. However, the effect of plastic stress on TP strain is not clarified. The present work found that the effect of plastic stress on TP strain is obviously different from the elastic stress. Firstly, compared to the sample with elastic stress, the variant selection is much more obvious under the effect of plastic stress due to the combined effect of prior deformation and stress, so the TP strain increases much faster versus plastic stress. In addition, the TP strain has close relationship with the transformation temperature. Moreover, there is a debate whether the occurrence of TP strain is caused by Magee mechanism or Greenwood-Johnson mechanism. The present work confirms that the occurrence of TP strain in the carbide-free bainite steel is consistent with the Magee mechanism.

In addition, it was stated by Matsuzaki et al. [30] that the TP strain about $14 \%$ is possible if all transformation is to the most favored variant, although the maximum TP strain in their study is only $\sim 5.5 \%$. The measured TP strain in study by Shipway et al. was less than 2\% [2]. In the present study, TP strain as large as $9.1 \%$ was obtained, which is close to the prediction by Matsuzaki et al. The further work will confirm whether $14 \%$ TP strain is available.

\section{Conclusions}

Bainite transformation experiments with and without stress were conducted; SEM, TEM, and EBSD techniques were used to investigate the effect of plastic stress on TP strain. The main conclusions are given as follows:

1. The TP strain increases nonlinearly with the applied stress. It increases slowly versus the stress in the elastic region. When the stress exceeds the austenite yield limit, there is a sharp increase in the TP strain due to the combined effect of prior deformation and stress. With further increment in stress, the bainite transformation amount decreases, so the increasing rate of TP strain slows down.

2. EBSD results show that variant selection develops in the sample with stress. The occurrence of TP strain is consistent with the Magee mechanism.

3. The TP strain is more obvious at lower transformation temperatures due to the increased bainite transformation amount and more organized bainite structure.

Acknowledgments The authors gratefully acknowledge the financial supports from Major Projects of Technological Innovation of Hubei Province (No. 2017AAA116), National Natural Science Foundation of China (NSFC) (No. 51704217), and Projects of Science and Technology of Henan Province (No. 182102210463).

\section{References}

1. H.K.D.H. Bhadeshia, S.A. David, J.M. Vitek, R.W. Reed, Stress induced transformation to bainite in $\mathrm{Fe}-\mathrm{Cr}-\mathrm{Mo}-\mathrm{C}$ pressure vessel steel. Mater. Sci. Technol. 7, 686-698 (1991)

2. P.H. Shipway, H.K.D.H. Bhadeshia, The effect of small stresses on the kinetics of the bainite transformation. Mater. Sci. Eng. A 201, 143-149 (1995)

3. K. Hase, C. Garcia-Mateo, H.K.D.H. Bhadeshia, Bainite formation influenced by large stress. Mater. Sci. Technol. 20, 1499 1505 (2004)

4. S. Kundu, K. Hase, H.K.D.H. Bhadeshia, Crystallographic texture of stress-affected bainite. Proc. R. Soc. A 463, 2309-2328 (2007)

5. T.J. Su, E. Aeby-Gautier, S. Denis, Morphology changes in bainite formed under stress. Scripta Mater. 54, 2185-2189 (2006)

6. L. Tian, Q. Ao, S.L. Li, Bainite transformation affected by predeformation and stress in G55SiMoV steel. J. Mater. Res. 29, 2994-3001 (2014)

7. M.X. Zhou, G. Xu, J.Y. Tian, H.J. Hu, Q. Yuan, Bainitic transformation and properties of low carbon carbide-free bainitic steels with $\mathrm{Cr}$ addition. Metals 7, 263 (2017)

8. J.Y. Tian, G. Xu, M.X. Zhou, H.J. Hu, X.L. Wan, The effects of $\mathrm{Cr}$ and $\mathrm{Al}$ addition on transformation and properties in low-carbon bainitic steels. Metals 7, 40 (2017)

9. F.G. Caballero, H.K.D.H. Bhadeshia, Very strong bainite. Curr. Opin. Solid State Mater. 8, 251-257 (2004) 
10. F.G. Caballero, M.J. Santofimia, C. Garcia-Mateo, J. Chao, C. de Garcia Andres, Theoretical design and advanced microstructure in super high strength steels. Mater. Des. 30, 2077-2083 (2009)

11. X.Y. Long, J. Kang, B. Lv, F.C. Zhang, Carbide-free bainite in medium carbon steel. Mater. Des. 64, 237-245 (2014)

12. M.X. Zhou, G. Xu, H.J. Hu, Q. Yuan, J.Y. Tian, Comprehensive analysis on the effects of different stress states on the bainitic transformation. Mater. Sci. Eng. A 704, 427-433 (2017)

13. M.X. Zhou, G. Xu, L. Wang, H.J. Hu, Combined effect of the prior deformation and applied stress on the bainite transformation. Met. Mater. Int. 22, 956-961 (2016)

14. M.X. Zhou, G. Xu, Y.L. Zhang, Z.L. Xue, The effects of external compressive stress on the kinetics of low temperature bainitic transformation and microstructure in a superbainite steel. Int. J. Mater. Res. 106, 1040-1045 (2015)

15. M.X. Zhou, G. Xu, L. Wang, Q. Yuan, The varying effects of uniaxial compressive stress on the bainitic transformation under different austenitization temperatures. Metals 6, 119-130 (2016)

16. M.X. Zhou, G. Xu, H.J. Hu, Q. Yuan, J.Y. Tian, Kinetics model of bainitic transformation with stress. Met. Mater. Int. 24, 28-34 (2018)

17. G.I. Rees, P.H. Shipway, Modelling transformation plasticity during the growth of bainite under stress. Mater. Sci. Eng. A 223, 168-178 (1997)

18. M.J. Holzweissig, D. Canadinc, H.J. Maier, In-situ characterization of transformation plasticity during an isothermal austeniteto-bainite phase transformation. Mater. Character. 65, 100-108 (2012)

19. M.J. Holzweissig, D. Canadinc, H.J. Maier, In situ characterization of backstress effects on the austenite-to-bainite phase transformation. Scripta Mater. 67, 368-371 (2012)

20. C.L. Magee, Transformation kinetics, microplasticity and aging of martensite in Fe-31Ni. Ph.D. thesis, Carnegie Mellon University, Pittsburgh, 1966

21. G.W. Greenwood, R.H. Johnson, The deformation of metals under small stresses during phase transformations. Proc. R. Soc. Lond. 283A, 403-422 (1965)
22. L. Taleb, S. Petit, New investigations on transformation induced plasticity and its interaction with classical plasticity. Int. J. Plast. 22, 110-130 (2006)

23. M.C. Uslu, D. Canadinc, H.-G. Lambers, S. Tschumak, H.J. Maier, Modeling the role of external stresses on the austenite-tobainite phase transformation in $51 \mathrm{CrV} 4$ steel. Modelling Simul. Mater. Sci. Eng. 19, 45007-45023 (2011)

24. H.N. Han, D.W. Suh, A model for transformation plasticity during bainite transformation of steel under external stress. Acta Mater. 51, 4907-4917 (2003)

25. Z. Liu, K.F. Yao, Z. Liu, Quantitative research on effects of stresses and strains on bainitic transformation kinetics and transformation plasticity. Mater. Sci. Technol. 16, 643-647 (2000)

26. X.X. Zhang, G. Xu, X. Wang, D. Embury, O. Bouaziz, G.R. Purdy, H.S. Zurob, Mechanical behavior of carbide-free medium carbon bainitic steels. Metall. Mater. Trans. A 45A, 1352-1361 (2014)

27. H.S. Hasan, M.J. Peet, M.N. Avettand-Fènoël, H.K.D.H. Bhadeshia, Effect of tempering upon the tensile properties of a nanostructured bainitic steel. Mater. Sci. Eng. A 615, 340-347 (2014)

28. W. Gong, Y. Tomota, Y. Adachi, A.M. Paradowska, J.F. Kelleher, S.Y. Zhang, Effects of ausforming temperature on bainite transformation, microstructure and variant selection in nanobainite steel. Acta Mater. 61, 4142-4154 (2013)

29. H.K.D.H. Bhadeshia, Bainite in Steels, vol. 3 (Institute of Materials, Minerals \& Mining, London, 2015)

30. A. Matsuzaki, H.K.D.H. Bhadeshia, H. Harada, Stress affected bainitic transformation in a $\mathrm{Fe}-\mathrm{C}-\mathrm{S}-\mathrm{Mn}$ alloy. Acta Metall. Mater. 42, 1081-1090 (1994)

Publisher's Note Springer Nature remains neutral with regard to jurisdictional claims in published maps and institutional affiliations. 